\title{
Design Method of FRP Pipe for Oil Well Frontier
}

\author{
Takashi Shimosakon, Masaki Uhara, Taiga Tatsumi, Shinichi Tamura, Yoshinori Nishino*
}

NBL Technovator Co., Ltd., Osaka, Japan

\section{Email address:}

shimosakon@nbl-technovator.jp (T. Shimosakon), uhara@nbl-technovator.jp (M. Uhara), tatsumi@nbl-technovator.jp (T. Tatsumi), tamuras@nbl-technovator.jp (S. Tamura), nishino@nbl-technovator.jp (Y. Nishino)

\section{To cite this article:}

Takashi Shimosakon, Masaki Uhara, Taiga Tatsumi, Shinichi Tamura, Yoshinori Nishino. Design Method of FRP Pipe for Oil Well Frontier. International Journal of Oil, Gas and Coal Engineering. Vol. 3, No. 1, 2015, pp. 1-12. doi: 10.11648/j.ogce.20150301.11

\begin{abstract}
New technologies such as the centrifugal winding method and improved GPI screw joints have expanded the application performance and research results of fiberglass reinforced plastic pipes over their long-term development. This study describes a strength design method for new oil well pipes, which are required for untapping deep oil wells as existing oil and gas fields become depleted. The durability of these pipes must exceed 30 years. Here, we quantified the withstanding pressure (100 $\mathrm{MPa})$, depth $(7000 \mathrm{~m})$, heat resistance $\left(250^{\circ} \mathrm{C}\right)$ and the $\mathrm{pH}$ of the corrosion resistance $(\mathrm{pH}=2)$. We also propose a strength design method that specifies new OCTGs for a global standard; namely, the Global Oil \& Gas Pipe Institute (GPI) standard.
\end{abstract}

Keywords: OCTG, EOR, Oilfield, FRP Pipe Design Method, Joint Coupling, Corrosion Resistance

\section{Introduction}

This design method of the Global Oil \& Gas Pipe Institute (GPI) is related to the design of strengthened oil wells containing corrosion-resistant fiberglass reinforced plastic (FRP) pipes of GPI standard ${ }^{1)}$. The pipe construction is shown in Fig. 1. The design method encompasses the tubing of the oil well, casing, and line pipes. With reference to ASME and ASTM-related standards and based on many years of research, we have developed a new method for designing oil well pipe applications. Material manufacturing is inspected by the GPI traceability or in accordance with the ASME Code Case $\mathrm{N}-155$. Test procedures for quality assurance are subjected to the E oil majors of specification. Test methods for determining the acceptable levels of stress and strain must conform to GPI or ASTM. The technology and analysis methods for designing the GPI standard are described elsewhere ${ }^{2)}$.

\section{Design Basis}

\subsection{Conventional Design Method}

According to current design standards for FRP piping (ASTM, ASME), the material and thickness of the anticorrosion layer should be based on the deterioration and erosion properties of resin, while those of the reinforced layer should satisfy the required pipe strength. The allowable stress level of the reinforced layer should be decided from hydrostatic test results multiplied by a safety factor.

However, as has been confirmed through operational experience and design problems, such a macroscopic view of the design method cannot meet the FRP piping requirements under severe operating conditions, because the current rules do not necessarily consider the actual failure mechanism of FRP

Under internal pressure, FRP fails by the following mechanism: (1) Initiation of micro-cracks with sound and no growth; (2) Cracking of the anti-corrosion layer and subsequent penetration of water (weeping); and (3) Fast crack growth and bursting. Because the weeping pressure is controlled by cracking of the anticorrosion layer, the strain of the anticorrosion is critical in the piping design and must be evaluated. $^{2)-7)}$

Moreover, the average failure shear stress of the secondary bonding joint is known to reduce with increasing adhesive length of the thread cone and GPI joint.

Other phenomena requiring evaluation are the delamination by fluid flow and the material deterioration during long-term operation, which significantly reduce the pipe strength. However, these phenomena are largely overlooked in current design standards. Our new FRP piping design method includes regulations for evaluating the strength and delamination of the anticorrosion layer and secondary adhesive joint. The details are given below. ${ }^{8), 9)}$ 
The design method is based on 45 years' worth of research and experience by Dr. Yoshinori Nishino and colleagues. The corrosion-resistant layer strength and the strength of the secondary adhesive joints were evaluated by measuring the amount of distortion under the allowable stress and stress of the loaded material (the allowable distortion). This approach is based on the design method ${ }^{(10-15)}$ of OCTG constructed from FRP.

The design method is detailed below.

\subsection{Strength Design Method of the FRP Pipe Developed by $N B L$}

\subsubsection{Design Basis of Anticorrosion Layer}

Corrosion resistance and strength are the significant parameters in anticorrosion layer design. To ensure corrosion resistance, the constitution of the laminate materials must be appropriately selected and the layer constructed with sufficient thickness to last the designated lifetime.
Cracks in the anticorrosion layer are directly connected with pipe failure. Consequently, the strength of the anticorrosion layer depends on the allowable elongation of the laminate constitution, itself dependent on the design life of the FRP pipe. The above design basis is summarized in Table 1.

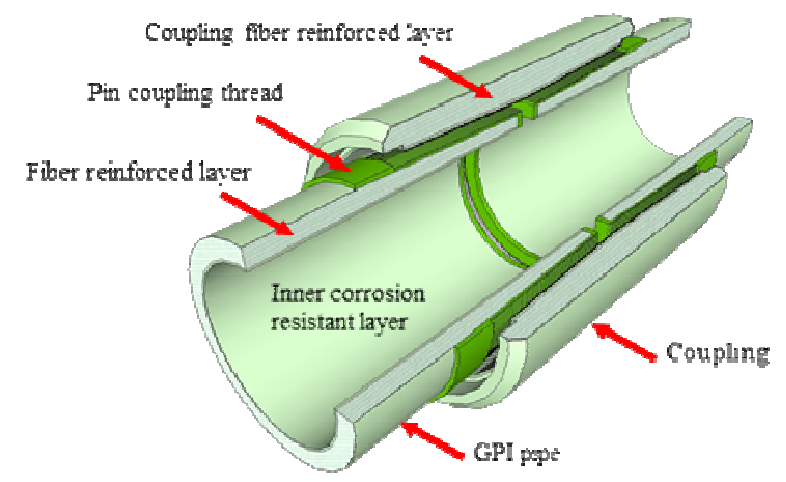

Fig. 1. Design of GRP OCTG.

Table 1. Design Basis of Anticorrosion layer.

\begin{tabular}{lll}
\hline Required Performance & Condition & Design Item \\
\hline \multirow{2}{*}{ Corrosion Resistance } & Environment, Fluid Condition & Selection of Laminate Constitution Material \\
& Design Life & Thickness of Anticorrosion layer \\
Strength & Maximum Elongation of Anticorrosion layer & Allowable Elongation of Liner \\
& Operation Load and Design Life & Safety Factor of Elongation \\
\hline
\end{tabular}

The maximum elongation of the resin layer varies not only with the kind of resin but also with its composition (that is, whether a corrosion resistant liner is included), as indicated in
Table 2. The effect of fatigue and creep on the allowable elongation is also considered.

Table 2. Maximum Elongation of Anticorrosion layer.

\begin{tabular}{lll}
\hline Laminate Components & Resin & Maximum Elongation (\%) \\
\hline Resin only & Urethane-modified epoxy & $6-18$ \\
& High-temperature imide-modified epoxy & $2-8$ \\
PS-15-69 & Urethane-modified epoxy & $1-2$ \\
Anticorrosion layer & High-temperature imide-modified epoxy & $0.4-0.9$ \\
\hline
\end{tabular}

The maximum elongation of the anticorrosion layer is easily and accurately determined by the testing method indicated in Table 2. This method imposes a punch load on a circular test piece of the anticorrosion layer material and the reinforced structural core. The strain on the anticorrosion layer is measured by a strain gauge attached to the surface.

By this method, the maximum strain is imposed at the center of the anticorrosion surface. Because the crack will not initiate from the circumferential edge, the maximum elongation of the anticorrosion layer can be accurately measured by the strain gauge output. This method may also confirm the integrity of the interface between the anticorrosion layer and the reinforced structural core under shear stress.

\subsubsection{Design Basis of Reinforced Structural Core}

The required properties of the reinforced structural core are stiffness and strength. The stiffness must maintain the strain of the anticorrosion layer below the allowable limit, while being sufficiently durable to withstand constant, cyclic, and transient loads during operation within its designed life. The stiffness and strength of FRP pipes depends on both the pipe thickness and the laminate material constitution (denoting the content ratio and orientation of the fibers). In the structural design, the fatigue of FRP during operation depends on creep and long-term deterioration. The design items of the reinforced structural core are listed in Table 3.

Table 3. Design Basis of Reinforced Structural Core.

\begin{tabular}{lll}
\hline Required Performance & Condition & Design Item \\
\hline \multirow{2}{*}{ Stiffness } & Allowable Elongation of Anticorrosion layer & Selection of Laminate Constitution Material \\
& Allowable Elongation of Reinforced Structural Core & Pipe Thickness Choice of Material \\
Strength & Allowable Stress & Pipe Thickness \\
\hline
\end{tabular}




\subsubsection{Design Basis of Joint}

The pipe joint requires careful attention in the FRP piping design. In most current FRP piping designs, the strength of the FRP pipe joint is assumed to equal the adhesive strength of two plates, based on the mean shear stress.

However, experiments and analyses carried out by NBL Technovator Co., Ltd. have shown that the failure strength of the joints largely depends on the shear stress concentration in the adhesive layer. Therefore, multiplying the shear stress by a safety factor, as implemented in current design methods, may not be sufficiently conservative. As an example, the failure pressure (or weeping pressure) of pipe joints measured in hydrostatic tests is mainly controlled by the interfacial strength between the roving cloth layer and the chopped strand mat. In these tests, the mean shear stress reduces with increasing adhesive length. This trend occurs because the shear stress is concentrated around the edges of the adhesive layer, and the stress concentration factor is a function of the adhesive length and the stiffness of both layers.

The NBL design method allows either simplified analyses by algebraic expressions or detailed analyses based on finite element methods (FEMs). Simplified and detailed design methods require different safety factors. The orthotropic elastic properties of FRP are considered in the design analysis, and the allowable stress and strain is decided for each material. The optimal pipe thickness, geometry and dimensions are determined by trial and error.

\subsubsection{Calculation Basis}

In NBL design, the elastic constants of the laminate constituting materials are calculated by the linear law of mixtures or some other well-known equation (the common equations are listed in Appendix 2.) If necessary, equivalent elastic constants of the laminated wall can be calculated by the linear summation law.

In the simplified design method, the elastic constants obtained by one of the above equations are substituted into the algebraic expression shown in Section 3.

The detailed design method analyzes the stress by FEM. To this end, NBL has developed the FRP-X software, which performs two-dimensional plate, axisymmetric solid, and three dimensional shell analyses of anisotropic materials on a
PC. FRP-X calculates the fiber direction and elastic modulus element by element and outputs the stress and strain components parallel and normal to the fiber. An auxiliary program, FRP-MESH, automatically generates a proper mesh from limited input data on the dimensions and material composition of the joint. It also computes the elastic constants of each material, the nodal coordinates, the node numbers composing each element, and the fiber direction of each element. Given the geometry and dimensions of the joint and the laminate constitution, the optimized joint that satisfies the stress and strain criteria at minimal cost is designed by trial and error. For example, the most-recently submitted design of the pipe joints is based on approximately 50 calculations, varying the geometry and material in each case. Incidentally, the complete set of analyses was completed in 10 hours, including preparation of the input data.

NBL is currently focused on investigating the fatigue strength and long-term deterioration of FRP materials and structures and will propose a life prediction method within a few years. Next, NBL plans to develop a CAD system for FRP structural design. Combining FRP-X, FRP-MESH, and a post processor, the CAD system will evaluate the FRP-X result with reference to the design criteria. The system will also include drawing software for displaying figures, tables, and documents. Moreover, NBL has established a failure simulation analysis method for the joint portion based on a nonlinear spring model. This simplified nonlinear technique simulates the entire failure process within a calculation time only $20-30 \%$ higher than required for linear analysis.

\subsection{Design Basis}

\subsubsection{Basic Pipe Specifications}

The pipe is constructed from the following materials:

Inner surface: The anticorrosive specifications are standardized in PS-15-69 (NBS).

Reinforced structure: Uses filament fiber reinforced core plastic.

Outer surface: Stacked anticorrosion layers.

The basic pipe dimensions are listed in Table 4. The nominal diameter is based on the inner diameter. The fitting dimensions will be shown later.

Table 4. Basic Pipe Dimensions.

\begin{tabular}{|c|c|c|c|c|c|}
\hline \multicolumn{3}{|c|}{ Tubing Pipe } & \multicolumn{3}{|c|}{ Casing \& Line Pipe } \\
\hline D inch & Pipe Length L (mm) & Thread & D inch & Pipe Length L (mm) & Thread \\
\hline $2-3 / 8$ & & & 5 & & \\
\hline $2-7 / 8$ & & & $5-1 / 2$ & & \\
\hline $3-1 / 2$ & & & 7 & & \\
\hline \multirow[t]{6}{*}{$4-1 / 2$} & & & $8-3 / 8$ & & \\
\hline & $9500 \mathrm{~mm}$ & GPI thread structure 8 round & $9-5 / 8$ & $9500 \mathrm{~mm}$ & GPI thread structure 8 round \\
\hline & & & $13-3 / 8$ & & \\
\hline & & & 20 & & \\
\hline & & & $23-3 / 8$ & & \\
\hline & & & 30 & & \\
\hline
\end{tabular}


The proper crest radius, total length of the thread root, and the taper angle of the thread, determined by detailed stress and strain analyses, may differ from the API standard.

\subsubsection{Materials}

- Raw materials

The raw materials are reinforced fiber: E glass fiber $(0.45$ $\mathrm{N} /$ tex or higher); filament $23 \mu ; \varepsilon_{\max } 2 \%$; laminated density 50 vol $\%$ or higher; circumferential direction: axial direction ratio $2: 1, \quad 1000-2000 \mathrm{~g} / \mathrm{m}^{2}$; uniform filament length $\pm 0.1 \%$; combination of non-woven fabric and CSM $100200 \mathrm{~g} / \mathrm{m}^{2}$; mat irrigation surface of $13 \mu ; 200$ filament; $50 \mathrm{~mm}$ cut.

The resin is epoxy-modified; $\mathrm{pH} 2$ or higher; $\varepsilon_{\max } 4 \%-18 \%$.

The usable temperature of resin ( 7 classes) ranges from its thermal deformation temperature $\left(60^{\circ} \mathrm{C}\right)$ to $250^{\circ} \mathrm{C}$.

-Quality control

Application: The material supplier is traceable by $\mathrm{GPI}^{16)}$ or by a guarantee program constructed for the QC system and materials in accordance with ASME NCA-3800 and NCA-4135.

GPI traceability standard: the pipe manufacturer should enter the QC information of the material suppliers individual product number, manufacturing information, and performance test information, for traceability of the individual product.

The user constructs and installs the product and its matching products, based on the traceability number and conditions of use, enters the applicable construction information, and applies the quality assurance traceability by GPI signatories via the internet.

\subsubsection{Design Scope}

New oil well pipe design specifications (GPI load and durability performance)

The new oil well pipe specifications in the GPI standard stipulate a load of Grade 4 withstanding pressure and a Grade 6 heat resistance, as shown in the table below. The required corrosion resistance is $\mathrm{pH} 2$, and (omitting the details) the short- and long-term endurance performance is 10 years and 50 years, respectively.

The standard length is $9.5 \mathrm{~m}$, and the GPI standard connection fittings are pin coupling screws. The oil well pipes consist of tubing, casing and line pipe (see GPI standard.)

A GPI application product is named by its diameter, withstanding pressure grade, and heat tolerance. For example, Product 3-1/2M150 has a 31/2-inch nominal diameter, a Grade $\mathrm{M}$ withstanding pressure, and a heat design grade of $150{ }^{\circ} \mathrm{C}$.

Table 5. GPI standard coupling (performance).

\begin{tabular}{|c|c|c|c|c|c|c|c|}
\hline $\begin{array}{l}\text { Withstanding } \\
\text { Pressure Grade }\end{array}$ & Tubing \& Casing & Line $\mathbf{F}$ & & $\begin{array}{l}\text { Designed } \\
\text { Pressure }\end{array}$ & $\begin{array}{l}\text { Short-term } \\
\text { Load }\end{array}$ & $\begin{array}{l}10 \text { years } \\
\text { Durability }\end{array}$ & $\begin{array}{l}50 \text { years } \\
\text { Durability }\end{array}$ \\
\hline E10 & Tap water well, $100 \mathrm{~m}$ & For wa & & $10 \mathrm{MPa}$ & $5 \mathrm{MPa}$ & $3 \mathrm{MPa}$ & $2 \mathrm{MPa}$ \\
\hline E20 & Tap water well, $200 \mathrm{~m}$ below & For wa & & $20 \mathrm{MPa}$ & $10 \mathrm{MPa}$ & $6 \mathrm{MPa}$ & $4 \mathrm{MPa}$ \\
\hline $\mathrm{E} 40$ & Hot spring wells, $1,500-4,000 \mathrm{~m}$ & Shale & & $40 \mathrm{MPa}$ & $20 \mathrm{MPa}$ & $12 \mathrm{MPa}$ & $8 \mathrm{MPa}$ \\
\hline G & $2,000-6,000 \mathrm{~m}$ for oil field & $\mathrm{CNG}_{\xi}$ & & $60 \mathrm{MPa}$ & $30 \mathrm{MPa}$ & $20 \mathrm{MPa}$ & $12 \mathrm{MPa}$ \\
\hline M & $3,000-9,000 \mathrm{~m}$ for oil field & Specia & e 1 & $80 \mathrm{MPa}$ & $40 \mathrm{MPa}$ & $26 \mathrm{MPa}$ & $16 \mathrm{MPa}$ \\
\hline $\mathrm{H}$ & $4,000-12,000 \mathrm{~m}$ for oil field & Specia & 2 & $100 \mathrm{MPa}$ & $50 \mathrm{MPa}$ & $33 \mathrm{MPa}$ & $20 \mathrm{MPa}$ \\
\hline $\begin{array}{l}\text { Withstanding } \\
\text { Temperature } \\
\text { (deg. C.) }\end{array}$ & $-20-60$ & $0-110$ & $25-250$ & $25-200$ & & \multicolumn{2}{|c|}{ Maximum 250} \\
\hline Temp. Grade & 60 & 110 & 150 & 200 & & \multicolumn{2}{|l|}{250} \\
\hline $\begin{array}{l}\text { Product } \\
\text { Marking }\end{array}$ & \multicolumn{7}{|c|}{$\begin{array}{l}\text { Examples of products } 2-7 / 8 \mathrm{G}-80 \text { : one coupling, in GPI tube with the other pin screw, outer diameter } 2-7 / 8 \text { inches, G grade } \\
\text { withstanding pressure, } 100 \text { degrees C. heat. } \\
\text { Examples of products } 5(\mathrm{~W}) \mathrm{E} 20-80 \text { : in GPI tube with both ends pin screw, outer diameter } 5 \text { inches (casing inner tube), E20 grade } \\
\text { withstanding pressure, } 80 \text { degrees C. heat. } \\
\text { Examples of products } 3-1 / 2 \mathrm{M}-100: 3-1 / 2 \text { inches at GPI coupling, pressure-resistant M grade, } 100 \text { degrees C. heat. }\end{array}$} \\
\hline
\end{tabular}

Reference: API standard pipe design specifications

Long-term load: Internal pressures up to $3000 \mathrm{psi}(21 \mathrm{MPa})$ are imposed by the buried soil pressure, and self-restraint loads are imposed by heavy thermal expansion and the piping reaction force.

Short-term load (for buried piping only): This constitutes the load associated with the track. The short-term maximum load is $4000 \mathrm{psi}$ (28 MPa).

Transient vacuum load: $-1.0 \mathrm{kgf} / \mathrm{cm}^{2}$.

Other loads: These include the wind load, the vibration load during an earthquake, and the restraint load due to anchoring.

Heat resistance: thermal stress and buckling; no special provisions are made for these.

Corrosion resistance: acid degradation; no special provisions are made for this.

Useful life: up to 30 years (medium-term 10 years). Under varying load, the estimated number of repetitions should be biased toward safety. If many repetitions are expected but their number is difficult to estimate, the repetition number should be set to $10^{7}$.

\section{- Evaluation}

To confirm acceptable stress and strain under long-term loading, the fatigue, creep, and aging properties are evaluated.

All combinations of short-term loads, which may act as long-term loads, are evaluated in the same manner.

- Other checks

GPI standard compliant. 


\section{Design}

\subsection{Design of Corrosion-Resistant Layer}

The material composition of the FRP pipe is shown in Fig. 2. The corrosion resistant resin and the isopthalic epoxy-modified resin system (urethane, novolac, polyimide) both satisfy the required acid resistance of $\mathrm{pH}=2$.

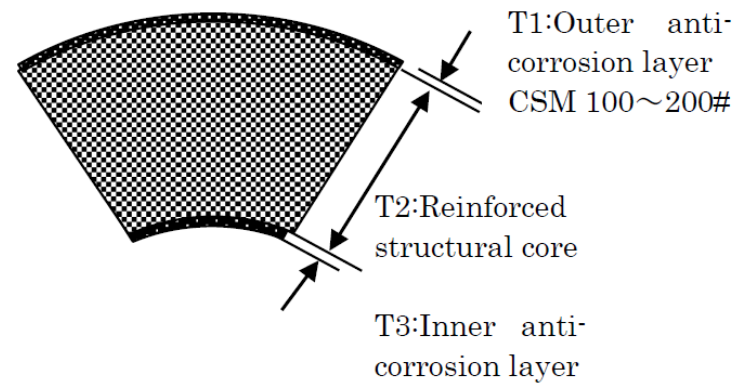

Fig. 2. Construction of FRP Pipe.

\subsubsection{Corrosion-Resistant Layer Configuration Resin Material}

$\mathrm{T}_{1}$ layer: The resin content of the outer anti-corrosion layer is approximately $80 \mathrm{wt} \%$.

$\mathrm{T}_{2}$ layer: The reinforced structure core comprises about 30 $\mathrm{wt} \%$ (50\% vol) resin.

$\mathrm{T}_{3}$ layer: The inner anti-corrosion layer is almost completely made of resin $(\sim 100 \mathrm{wt} \%)$.

\subsubsection{Thickness of Anti-Corrosion Layer}

The thickness of the T1 and T3 layers is finally decided from the inner diameter of the FRP pipe, the corrosive fluids, and the required abrasion resistance.

In the oil well pipe specifications of the GPI OCTG standard, the corrosive fluids are oil and gas in water, corrosive $\mathrm{H}_{2} \mathrm{~S}$ ( 1 bar), carbon dioxide (1 bar) saturated brine; other specifications are a maximum flow rate of $2 \mathrm{~m} / \mathrm{s}$ and an ambient temperature up to $250{ }^{\circ} \mathrm{C}$. If the fluid contains fine particles such as sand, corrosive wear must be considered even at low speed. To satisfy these requirements, the thicknesses of the layers are given as:

- Outer anticorrosion layer ( $\mathrm{T}_{1}$ layer $): 0.1-0.2 \mathrm{~mm}$, CSM100-200\#1Ply laminated

- Inner anticorrosion layer ( $\mathrm{T}_{3}$ layer): 0.5-1.2 $\mathrm{mm}$ (average $1 \mathrm{~mm})$.

At normal corrosive levels (below $\mathrm{pH}$ 2), corrosive wear is negligible. Lamination is needed only if corrosive fluid directly contacts the resin.

\subsubsection{Maximum Elongation of Anticorrosion Layer}

The test piece is circularly configured when the circumferential and axial strains on the inner surfaces of the FRP pipe are of similar magnitude. As the ratio of the circumferential to axial strain increases, the configuration becomes more elliptical.

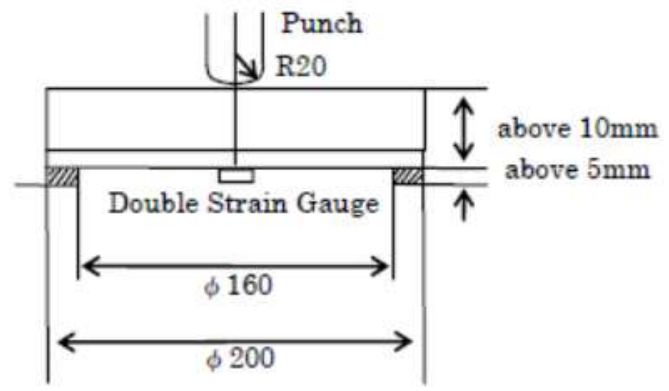

Fig. 3. Test method for determining the maximum elongation of anticorrosion layer.

As the anticorrosion layer cracks at the center of the circular test piece, where maximum strain is imposed, the bi-axial strain gauge should be attached there. Crack initiation is visually checked and is also detected by a discontinuity in the strain output. The allowable elongation is the strain immediately before crack initiation. The maximum elongation at high temperature is measured by placing the test piece in a constant-temperature oven.

\subsubsection{Test Method for Corrosion Deterioration}

Fig. 4 schematizes the test method for corrosion deterioration designed by NBL Co., Ltd. The FRP pipe is laterally compressed by a vice. A carbon steel plate is inserted between the vice and the outer pipe wall. The internal strain is measured by a compass and/or a strain gauge. Corrosive fluid is poured into the test pipe compressed at a constant rate until crack initiation. The change in the strain level and the elapsed time to crack initiation are measured as the parameters of compressive load.

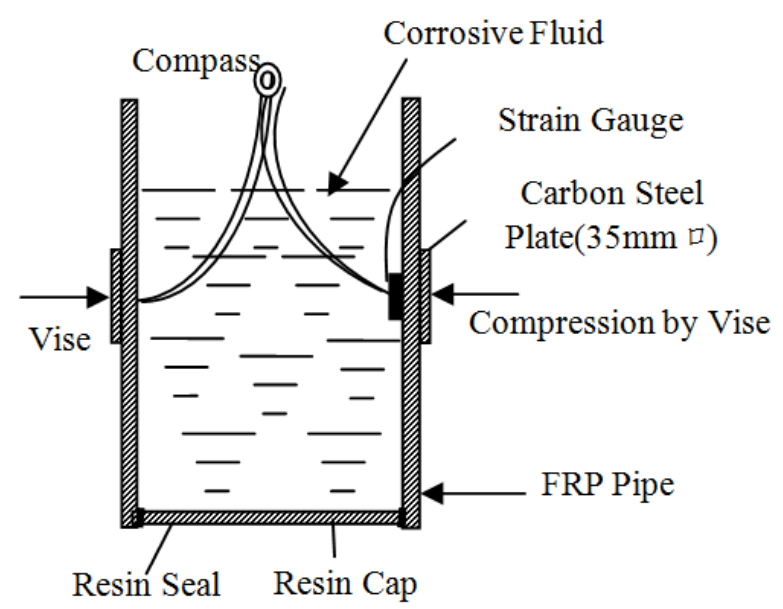

Fig. 4. Test method for corrosion Deterioration.

The chemical solution is identically placed (either vertically or horizontally) in all test samples. Tests in heated chemical solution, and under high-temperature high-pressure corrosion conditions, are also conducted in a pressure vessel.

The test time is $10-50$ years $\left(4 \times 10^{5}\right.$ hours). Durability evaluation, usually measured at four points, must be conducted at $0,10^{1}, 10^{2}, 10^{3}$, and $10^{4}$ hours, at a minimum. To determine the accuracy, we require the allowable load at $10^{4}$ 
hours (the maximum elongation). On the other hand, a short-term deterioration test on a single resin test piece is effective if the allowable elongation is proportional to the weight change. This test evaluates whether high concentrations of the corrosive accelerate corrosion degradation. In the GPI standard, the test piece is immersed in acetic acid stock solution ( $\mathrm{pH} 0.2)$ and heated to $95{ }^{\circ} \mathrm{C}$. The $\mathrm{pH} 2$ oxidation performance is then compared before and after a weight change (at 10 hours).

\subsubsection{Determination of Allowable Elongation}

To determine the deterioration factor $C_{D}$ over the designed life, the relation between the initial strain of the anticorrosion layer and the crack initiation time obtained by the corrosion deterioration test is extrapolated to long-term behavior. The allowable elongation limit $e_{a}$ is calculated by

$$
e_{a}=C_{\dot{S}} \mathrm{C}_{\mathrm{D}} e
$$

where the variables are defined as follows:

$$
\begin{aligned}
& C_{s} \text { : Safety factor } \\
& C_{D} \text { : Deterioration factor } \\
& e: \text { Maximum elongation of the anticorrosive layer }
\end{aligned}
$$

\subsubsection{Calculation of Strain on the Anticorrosion Layer}

The strain on the anticorrosion layer is calculated by a simplified equation or by detailed FEM analysis. This specification will be applied to crude oil piping; therefore the important load is the internal load. The strain on the inner anticorrosion layer under internal pressure can be simply calculated as follows:

$$
\begin{gathered}
\varepsilon_{\theta}=\frac{P}{E} \frac{(1+v) d_{0}^{2}+(1-2 v) d_{i}^{2}}{2 t\left(d_{0}+d_{i}\right)} \\
\varepsilon_{\ell}=\frac{P}{E} \frac{(1-2 v) d_{i}^{2}}{2 t\left(d_{0}+d_{i}\right)}
\end{gathered}
$$

$\varepsilon_{\theta}:$ Circumferential strain

$\varepsilon_{\ell}:$ Axial strain

$P$ : Internal pressure

$d_{0}$ : Outer pipe diameter

$d_{i}$ : Inner pipe diameter

$t:$ Pipe thickness

$E$ : Elastic modulus of pipe

v: Poisson's ratio

If the axial and circumferential elastic moduli are significantly different, the smaller modulus is assumed.

\subsection{Design of Reinforced Structural Core}

\subsubsection{Material}

The reinforcing fibers' response to the direction of the force acting on the pipe should not exceed 30 inch and the pressure should remain below $100 \mathrm{MPa}$. These conditions are satisfied by E-Glass $23 \mu$ (direct-roving $0.45 \mathrm{~N} /$ tex; circumferential axis 2:1; glass oriented without distortion in bamboo; blind knitting of fiber). In addition to the high-strength tube, S-Glass reinforcing fibers $(0.55 \mathrm{~N} /$ tex or higher $)$ should be used. The reinforcing fibers are laminated such that all continuous fibers (content $70-73 \mathrm{wt} \%$ ) are of uniform tension. The maximum elongation at break of the reinforcing fibers is decided as $2 \%$.

The matrix resin defines the coverage at the heat distortion temperature. The material is tested in six temperature categories; $60{ }^{\circ} \mathrm{C}$ or less, $80 \mathrm{C}^{\circ}, 110 \mathrm{C}^{\circ}, 150 \mathrm{C}^{\circ}, 200^{\circ} \mathrm{C}$, and $250{ }^{\circ} \mathrm{C}$. The tolerance of acid resistance durability is at least $\mathrm{pH} 2$. In the allowed elongation test, a polymer blend of resin was composited to obtain the required stretch. The minimum elongation of some resins, before the test sample burst without weeping under the internal pressure, was $8-12 \%$.

\subsubsection{Minimum wall thickness $\left(t_{m c}, t_{m \ell}\right)$}

- Under circumferential stressors, the minimal wall thickness is given by

$$
t_{m c}=\frac{P D_{0}}{2 S_{c}}+B
$$

$B$ : Additional thickness to allow for the extra stress imposed by grooving, damage caused by installation, operation, maintenance and inspection, and erosion (which will reduce the wall thickness), and by the additional bending moment

$S_{\ell}$ : Allowable stress under longitudinal tension

$S_{c}$ : Allowable stress under circumferential tension

- Under longitudinal stressors, the minimal wall thickness is given by

$$
t_{m \ell}=\frac{P D_{0}}{2 S_{\ell}}+B
$$

- The selected minimum wall thickness is the larger of (4) or (5).

$$
t_{m}=\operatorname{Max}\left(t_{m c}, t_{m \ell}\right)
$$

\subsubsection{Design for Buckling} by

- The moment of inertia under lateral load bending is given

$$
\mathrm{I}=\frac{\pi}{64}\left(d_{0}^{4}-d_{i}^{4}\right)
$$

where $d_{0}$ and $d_{i}$ denote the outer and inner diameters, respectively.

If the pipe is thin, we have

$$
\begin{gathered}
\mathrm{I}=\frac{\pi}{8} d^{3} t \\
d=\frac{1}{2}\left(d_{0}+d_{i}\right)
\end{gathered}
$$

Under cross-sectional bending, the moment of inertia is 


$$
\mathrm{I}=\frac{b t^{3}}{12\left(1-v^{2}\right)}
$$

where $t$ is the pipe thickness, and $b$ is the length of the cylinder

- Moment of inertia of a stiffened cylinder

Assuming that the circumferential and axial stiffness sufficiently guard against external pressure buckling and axial buckling respectively, we have

$$
\mathrm{I}^{*}=\mathrm{I}_{0}+\frac{\mathrm{I}_{s}}{L_{e}}
$$

$I^{*}$ : Equivalent moment of inertia of cylinder reinforced with stiffener

$\mathrm{I}_{s}:$ Moment of inertia of stiffener

$\mathrm{I}_{0}$ : Moment of inertia of cylinder alone

$$
L_{e}:=\mathrm{I}(\text { axial buckling })=\operatorname{Min}\left\{\frac{\sqrt{2 d_{0} t}}{\left[3\left(1-v^{2}\right)\right]^{\frac{1}{4}}}, L\right\}
$$

(circumferential buckling)

$L:$ Interval of the stiffener

- The limiting pressure for axial buckling is given by

$$
P_{c r}=\left(\frac{m^{2} \pi^{2} E_{\ell} t^{2}}{12\left(1-v^{2}\right) \ell^{2}}+\frac{4 E_{\theta} \ell^{2}}{m^{2} \pi^{2} d^{2}}\right) \frac{1}{S_{F}}
$$

$E_{\ell}:$ Axial elastic modulus

$E_{\theta}$ : Circumferential elastic modulus

$v$ : Poisson's ratio

$\ell:$ Length of cylinder (interval of stiffener)

$t$ : Pipe wall thickness

$d$ : Diameter of cylinder

$S_{F}:$ Safety factor $(=3.0)$

$m:$ Integer

- The limiting external pressure for buckling (excluding the burial pressure) is given by $L_{c}=k d \sqrt{\frac{d}{t}}>L:$

General buckling needs to be considered when

$$
\begin{aligned}
& P_{c r}=\frac{3.615 E}{2.432+(D / L)^{2}}\left(\frac{t}{D}\right)\left[\left(\frac{t}{D}\right)^{2}\left(1.216+\frac{D^{2}}{L^{2}}\right)^{2}+\frac{0.4484(D / L)^{4}}{\left(1.621+D^{2} / L^{2}\right)^{2}}\right] \\
& \text { (d) } \frac{D}{t}<0.524\left(\frac{L}{D}\right)^{2} \quad P_{c r}=2.2 E\left(\frac{t}{D}\right)^{3}
\end{aligned}
$$

2) Elastic general buckling pressure

$$
P_{c r}=\frac{8\left(n^{2}-1\right) E\left[\mathrm{I}_{0} L+\mathrm{I}_{s}\right]}{D^{3} 2 L_{e}}+2 E\left(\frac{t}{D}\right) \frac{\lambda_{b}{ }^{4}}{\left[f^{\prime}\left(n^{2}-1\right)+0.5 \lambda_{b}{ }^{2}\right]\left(n^{2}+\lambda_{b}{ }^{2}\right)^{2}}
$$




$$
\begin{aligned}
& \lambda_{b}=\frac{\pi D}{2 L_{0}} \quad L_{0}: \text { Total length of cylinder } \\
& f^{\prime}=\frac{1}{1+\frac{A_{f}}{t L}} \quad A_{f}: \text { Cross-section area of stiffener }
\end{aligned}
$$

where shell plate buckling may be critical, the stiffener will be sufficiently rigid to provide a $>10 \%$ safety margin against buckling.

3) Axisymmetric collapse is given by

$$
P_{c r}=\frac{2 t \sigma_{y}}{d}
$$

(1) Safety factor

The buckling pressure limit of the buried pipe is

$$
P_{c r}=\frac{1}{S_{F}} \sqrt{32 R_{w} B^{\prime} E^{\prime} \frac{E \mathrm{I}^{*}}{d^{3}}}
$$

$R_{w}=1-0.33 \frac{h_{w}}{h}:$ Coefficient of water buoyancy

$h_{w}:$ Water height from the top of the pipe

$h$ : Ground height from the top of the pipe

$B^{\prime}$ : Coefficient of elastic support $\left(=\frac{1}{1+4 e^{-0.065 H}}\right)$

$H$ : Burial depth above the top of the pipe (ft)

$E^{\prime}$ : Elastic modulus of soil

$E \mathrm{I}^{*}$ : Equivalent bending rigidity of the pipe

$d$ : Pipe diameter

$S_{F}:$ Safety factor $(=3.0)$

\subsubsection{Design for Long-Term Load}

Long-term load includes the internal pressure, the pressure due to soil weight (which acts on buried pipes only), and the reaction and constrained forces on the pipe caused by thermal expansion.

$$
\frac{P D_{0}}{4 t_{m}}+0.75 \frac{i M_{A}}{Z}+\frac{i M_{C}}{Z} \leq S_{\ell}
$$

$P:$ Internal pressure - soil pressure

$D_{0}$ : Outer pipe diameter

$t_{m}$ : Thickness of reinforced structural core

$Z$ : Section modulus of pipe, $\left(=\frac{\pi D^{2} t_{m}}{4}, \mathrm{D}:\right.$ Mean dia. $)$

$i$ : Stress intensification factor $(0.75 \mathrm{i} \geqq 1.0)$

$M_{A}$ : Bending moment due to the weight load and other sustained loads

$M_{C}$ : Bending moment imposed on the piping system by thermal expansion, internal pressure deformation and anchor displacement

\subsubsection{Design for (Short-Term Load) + (Long-Term Load)}

Short-term load includes transient over-pressure, truck load (on buried pipes), and other loads such as seismic, wind, and impact loads. As long-term and short-term loading can simultaneously occur, both load classes are combined in the design.

$$
\frac{P_{\max } D_{0}}{4 t_{m}}+0.75 i \frac{\left(M_{A}+M_{B}\right)}{Z}+\frac{i M_{C}}{Z} \leq 1.2 S_{\ell}
$$

$P_{\max }:$ Peak pressure

$M_{B}$ : Bending moment imposed by transient over-pressure, earthquakes, strong wind, impact and trucks passing (above buried pipes only)

\subsubsection{Detailed Analysis of Piping}

If criteria (4) and (5) are not satisfied, a detailed stress analysis of the entire piping system is recommended. The design should consider the rationalized allowable stress obtained in the detailed analysis.

\subsection{Design of Joint}

Provided that the reinforced structural core is designed according to the criteria described in Section 3.2, the joint portion will not fail under normal stress. However, failure of the joint portion can initiate from the adhered layer; specifically, the interface between the mat and roving layers. Therefore, the adhered layer should be designed such that the actual shear stress is below the allowable level.

The shear stress of the adhesive layer is highest at the edge of the secondary portion, as indicated in Fig. 6.

$$
\begin{gathered}
\tau_{1}=\frac{F C\left(E_{1} t_{1}+E_{2} t_{2} \cosh C \ell\right)}{\pi d\left(E_{1} t_{1}+E_{2} t_{2}\right) \sinh C \ell} \\
\tau_{2}=\frac{F C\left(E_{1} t_{1} \cosh C \ell+E_{2} t_{2}\right)}{\pi d\left(E_{1} t_{1}+E_{2} t_{2}\right) \sinh C \ell} \\
\tau_{\max }=\operatorname{Max}\left(\tau_{1}, \tau_{2}\right)
\end{gathered}
$$

$F$ : Axial load on the joint portion

$$
C=\sqrt{\frac{G_{0}}{H}\left(\frac{1}{E_{1} t_{1}}+\frac{1}{E_{2} t_{2}}\right)}
$$

$G_{0}$ : Shear modulus of the adhesive layer

$H$ : Thickness of adhesive layer

$E_{1}, E_{2}$ : Elastic modulus of material 1.2

$t_{1}, t_{2}$ : Pipe thickness of range 1.2

$\ell$ : Length of adhesive layer

$d$ : Diameter of adhesive layer

- For long-term load

$$
\tau_{\max } \leq S_{\ell c}
$$


- For (short-term load) +(long-term load)

$$
\tau_{\max } \leq 1.2 S_{\ell c}
$$

$S_{\ell c}:$ Allowable shear stress

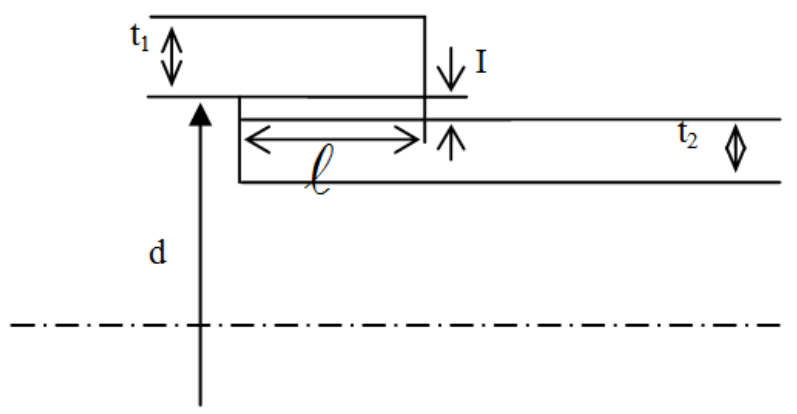

Fig. 5. Joint model.

- As stated above, for (short-term load) + (long-term load) we have

When conducting a detailed stress analysis of the joints, the results should determine the allowable stress in the design.

In determining the smallest allowable shear stress, the joint surface is assumed to taper at $1 / 16$. Other parameters are $\ell / t_{2}$ $=8-10$ and $I=2-4 \mathrm{~mm}$. The optimal screw on the joint surface is an 8-round screw.

\subsection{Design of Pin Coupling}

Figure 6 shows the load-stress coupling imposed by the screw joint. The sealing pressure P2 should be 1.5 times

$$
\tau_{\max } \leq 1.2 S_{\ell c}
$$

higher than the pressure load P1. The figure shows the required distribution of the shear stress imposed by the axial force acting on the threaded portion.

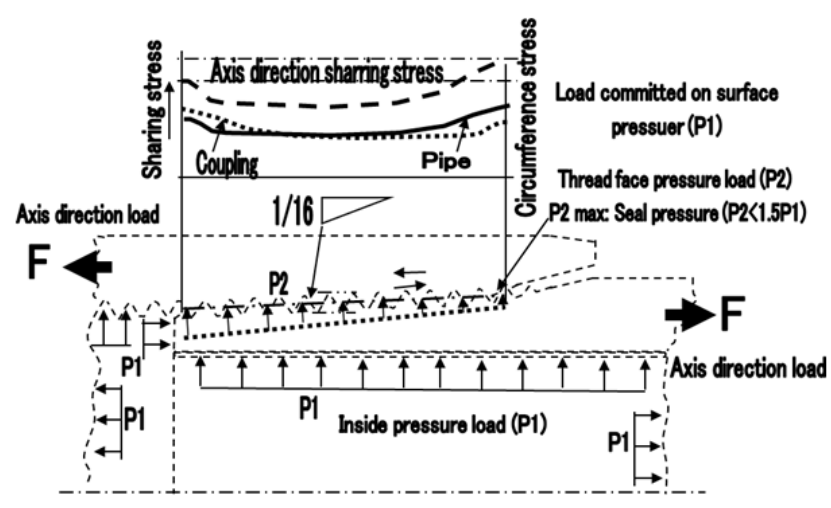

Fig. 6. Load and stress of the pin coupling screw joint.

The basic joint structures that ensure relaxation and distribution of the seal surface pressure imposed by the shear stress are illustrated in Fig. 7. This structure also ensures sufficient axial force to withstand the internal pressure.

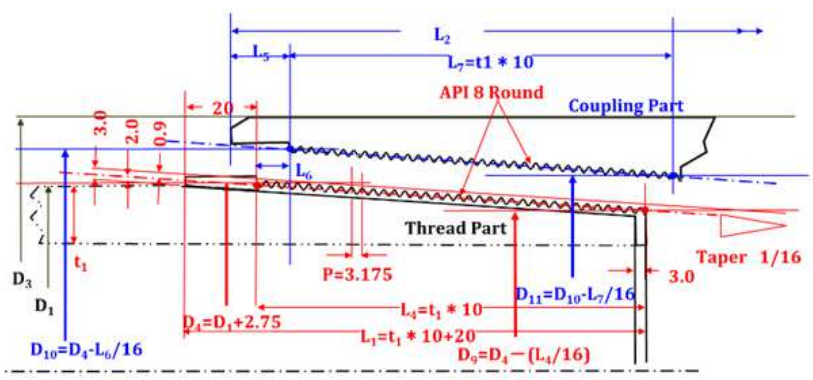

\begin{tabular}{|c|c|c|c|}
\hline $\begin{array}{l}\text { Base line and list of } \\
\text { GPI design }\end{array}$ & $\begin{array}{l}\text { Propo } \\
\text { rtion }\end{array}$ & Outline of criteria & $\begin{array}{l}\text { Constructio } \\
\text { n standard }\end{array}$ \\
\hline $\begin{array}{l}\mathrm{t} 1=1 / 3 \text { to } 1 / 5 \\
\text { of allowable stress }\end{array}$ & 1 & $\begin{array}{l}\text { necessary thickness design for allowable load should be under the condition } \\
\text { of less than } 10 \text { years life, } 1 / 3 \text { of burst stress, and } 1 / 5 \text { of performance in } 40 \\
\text { years. }\end{array}$ & $\begin{array}{l}\text { Durability } \\
\text { choice }\end{array}$ \\
\hline $\begin{array}{l}\text { D1=API steel pipe } \\
\text { std. OD }+3 \text { to } 4 \mathrm{~mm}\end{array}$ & 2 & $\begin{array}{l}\text { GPI std. OD have } 3 \text { to } 4 \mathrm{~mm} \text { plus to API std. OD for having anti-corrosive } \\
\text { layer }\end{array}$ & $\begin{array}{l}\text { Casing } \\
\text { applies the } \\
\text { same }\end{array}$ \\
\hline $\mathrm{L} 3=20 \mathrm{~mm}$ & 3 & To have $20 \mathrm{~mm}$ entrance to relief stress from grinding and notch & $\begin{array}{l}\text { 10mm for } \\
\text { low } \\
\text { pressure } \\
\text { application }\end{array}$ \\
\hline $\mathrm{L} 1=\mathrm{t} 1 *$ about 10 & 1 & $\begin{array}{l}\text { max. fabrication condition of effective length should be } 10 \text { times of } \\
\text { thickness }\end{array}$ & \\
\hline $\mathrm{t} 4=(1 / 3$ to $1 / 4) * \mathrm{t} 1$ & 2 & $\begin{array}{l}\text { thickness for allowable buckling to make sealing pressure (same as WP) by } \\
\text { tightening }\end{array}$ & \\
\hline $\mathrm{t} 5=2$ to $3 \mathrm{~mm}$ & 3 & thickness for allowable stress on edge and corrosion resistance & \\
\hline $\mathrm{L} 5=0.5$ to $1.5 * \mathrm{t} 1$ & 3 & length for making enough sealing pressure & \\
\hline $\mathrm{t} 2=0.03 * \mathrm{D} 1$ or more & 1 & thickness against vacuum buckling & \\
\hline $\mathrm{t} 3=1.5 * \mathrm{t} 2$ & 1 & stractural wall condition for sealing pressure & \\
\hline \begin{tabular}{|l|} 
applied API $1 / 16$ \\
taper 8 round thread
\end{tabular} & 1 & suitable angle for stress relief, related to $L 1$ & \\
\hline $\begin{array}{l}\text { Thread: API } 8 \text { round } \\
\text { (Fig12) }\end{array}$ & 2 & RTC by resin only for stress dispersion, different from API OCTG thread & \\
\hline $\begin{array}{l}\text { QC: sf } 1.5 \text { times of } \\
\text { WP }\end{array}$ & 2 & $\begin{array}{l}\text { QC test applies } 10 \mathrm{MPa} \text { to hotspring grade, } 20 \mathrm{MPa} \text { to } \mathrm{E}, 30 \text { to } \mathrm{G}, 40 \text { to } \mathrm{M} \text {. } \\
50 \text { to } \mathrm{H} \text {. (test load is } 1.5 \text { times of WP) }\end{array}$ & 2 mins \\
\hline $\begin{array}{l}\text { need to have surface } \\
\text { compress on thread }\end{array}$ & 2 & $\begin{array}{l}\text { tightening torque for surface pressure same to WP. Sealing materials will be } \\
\text { chosen due to each purpose }\end{array}$ & $\begin{array}{l}\text { torque } \\
\text { control }\end{array}$ \\
\hline
\end{tabular}

Fig. 7a. Basic structure of the pin coupling screw.

Fig. 7b. Basic structure of pin coupling screw. 
The basic structure of the joints using an 8-round screw exploits the characteristics of an FRP-specific ratio rigid pipe by providing a corrosion-resistant layer resin layer on the internal surface that contacts the fluid. Stress relaxation is necessary such as to transmit the pressure load on the sealing surface.

\subsection{Allowable Stress}

The allowable stress is decided by the following tests:

(1) Time-to-Failure of Plastic Pipe Under Constant Internal
Pressure (ASTM D1598)

(2) Cyclic Pressure Strength of Reinforced, Thermosetting Plastic Pipe (ASTM D2143)

(3) Longitudinal Tensile Properties of Reinforced Thermosetting Plastic Pipe and Tube (ASTM D2105)

(4) Fatigue Test of Reinforced Thermosetting Plastic Pipe with a Joint at the Central Region Under Cyclic Axial Tension Load

The strengths evaluated by each of these tests are listed in Table 6.

Table 6. Strength of FRP Pipe under Various Tests.

\begin{tabular}{|c|c|c|c|c|c|c|}
\hline \multirow{2}{*}{ Test Classification } & \multicolumn{3}{|c|}{ Short-Time Strength } & \multicolumn{3}{|c|}{ Long-Time Strength } \\
\hline & Axial & Circumferential & Shear & Axial & Circumferential & Shear \\
\hline Hydrostatic Test & & $\begin{array}{l}\text { (1) } \\
\mathrm{S}_{\mathrm{cl}} \\
\text { (2) }\end{array}$ & $\begin{array}{l}\text { (1) } \\
S_{\ell c_{1}}^{\prime} \\
\text { (2) }\end{array}$ & & $\begin{array}{l}\text { (1) } \\
\mathrm{S}_{\ell 2} \\
(2)\end{array}$ & $\begin{array}{l}\text { (1) } \\
\mathrm{S}_{\text {fc2 }} \\
\text { (2) }\end{array}$ \\
\hline $\begin{array}{l}\text { Tension } \\
\text { Test }\end{array}$ & $S_{\ell_{1} \text { (3) }}$ & - & $S_{\ell c_{1}}^{\prime}(3)$ & $S_{\ell_{2}}$ (4) & - & $S^{\prime}{ }_{\ell c_{2}}$ (4) \\
\hline
\end{tabular}

Defining the internal bursting pressure by $\mathrm{P}$,

$$
S_{c}=\frac{P(D-t)}{2 t}
$$

where $t$ is the pipe thickness, and $D$ is the outer pipe diameter. We also define

$$
F=\frac{P(D-2 t)^{2}}{4(D-t)}
$$

$S_{\ell c}$ is obtained by substituting $F$ into the equation of shear stress in the adhesive layer, introduced in Section 3.3.

The allowable short- and long-term stresses are calculated as follows:

The allowable stress for short-term stress is

$$
\begin{aligned}
& S_{\ell}=\frac{1}{S_{F_{1}}} S_{\ell_{1}} \quad S_{c}=\frac{1}{S_{F_{1}}} S_{c_{1}} \\
& S_{\ell c}=\frac{1}{S_{F_{1}}} \operatorname{Min}\left(S_{\ell c_{1}} \cdot S^{\prime}{ }_{\ell c_{1}}\right)
\end{aligned}
$$

The allowable stress for long-term stress is

$$
\begin{gathered}
S_{\ell}=\frac{1}{S_{F_{2}}} S_{\ell_{2}} \quad S_{c}=\frac{1}{S_{F_{2}}} S_{c_{2}} \\
S_{\ell c}=\frac{1}{S_{F_{2}}} \operatorname{Min}\left(S_{\ell c_{2}} \cdot S_{\ell c_{2}}^{\prime}\right)
\end{gathered}
$$

Safely factor:

The simplified analysis based on the algebraic expression provides the following safety factor specification

$$
S_{F_{1}}=S_{F_{2}}=3.0
$$

while the detailed stress analysis gives

$$
S_{F_{1}}=S_{F_{2}}=2.5
$$

\subsection{Allowable Stress and Temperature Dependence}

The allowable stress is affected by the thermal deformation temperature $(\mathrm{Tg})$ of the resin. When the temperature approaches the $\mathrm{Tg}$ of the resin, the pressure tensile stress tolerance exceeds the resin degradation by approximately $25 \%$, and the buckling under compressive strength exceeds the resin degradation by about $60 \%$.

The GPI pipe design is based on the concept of priority-thermal destruction; the priorities are destroying the internal pressure caused by oil-gas extraction (measured by the tensile strength and rigidity of the matrix material to cracking), and reducing the axial thermal stress imposed by the temperature difference generated during mining (achieved by lowering the coefficient of expansion).

In this design philosophy, the reinforcing fiber is strengthened against circumferential cracking by adopting a soft (high elongation) resin matrix. Next, the coefficient of thermal expansion is reduced to lessen the thermal stress generated by the temperature difference. We measure the stiffness reduction that allows the orientation and thermal deformation of the anisotropic reinforcing fibers in the laminated flexible resin. That is, rather than increase the allowable stress in the axial direction, we reduce the thermal expansion coefficient by lowering the material rigidity. In this design, the pipe can withstand the thermal stress generated within the allowable heat resistance of the resin.

Accordingly, the withstanding pressure of the acceptable crushing-buckling strength of the laminated pipe is lowered, while the withstanding pressure and heat resistance of the pipe is increased. Together, these measures improve the pipe performance is improved.

By this approach, the lowest acceptable compressive 
strength is about $40 \%$ of the axial tensile strength determined from the design and test results $(100 \mathrm{MPa})$. The heat degradation is reduced by $10 \%$ at the maximum allowable temperature, and finally contributes around $30 \%$ of the allowable stress $(75 \mathrm{MPa})$. Thus we have designed an oil well pipe that can withstand the target internal pressure of $100 \mathrm{MPa}$, a maximum temperature difference of $250^{\circ} \mathrm{C}$, and a corrosion resistance of $\mathrm{pH} 2$. The expected durability of the oil well pipe is 50 years.

\section{Quality Assurance}

The quality assurance program of the OCTG interpolates the IC chip along with the visible character information and the bar code information display, which are visible from outside of the pipe surface with the internal pipe surface.

The design information from which the final material load test was devised and the specified durability period is maintained, is provided in the database. The information can be confirmed via the Internet, according to the GPI traceability ${ }^{16)}$ provided by a third party or by the API standard quality assurance testing program. Detailed information is omitted.

In the GPI quality assurance program, the product traceability may be subjected to a preferred insurance system, such as PL liability insurance guarantees.

\section{Conclusion}

This work has described the basic design theory by which we produce strong, durable (expected lifetime $=50 \mathrm{y}$ ) oil well pipes. The pipes can withstand a pressure of $100 \mathrm{MPa}$ and a depth of $7000 \mathrm{~m}$. In addition, they are heat-resistant to $250^{\circ} \mathrm{C}$ and anti-corrosive to a $\mathrm{pH}$ of 2 . The material constants derived by the applied stress analysis are presented in the Appendix (the theoretical details of the analysis are omitted).

In designing the pipe deployment, we drew on long-term research by the authors, some of which is provided in the reference list.

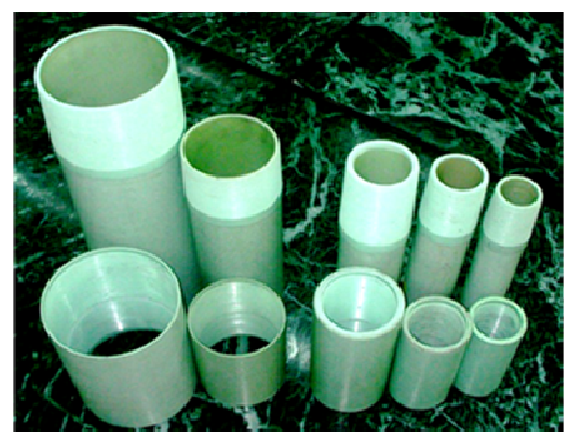

Fig. 8. Examples of products manufactured under the proposed design theory.

The present strength design method for FRP pipes in new oil wells is based on the design logic of OCTG in the GPI technology standard. Examples of pipes satisfying the GPI standards are photographed in Fig. 8. These pipes have been commercially available since 2009 and have made a significant contribution to the market

PS: For OCTG applications, please refer to the GPI standard. (http://gpi-pipe.org)

\section{Acknowledgement}

This manuscript is certified by the Global Oil \& Gas Pipe Institute (GPI) which provided valuable comments.

GPI homepage (URL: http://www.gpi-pipe.org/)

\section{Appendix: Material Constants Formulae}

\section{A.1: Glass content}

$$
V_{f}=\frac{W_{f} \rho_{m}}{W_{f}\left(\rho_{m}-\rho_{f}\right)+\rho_{f}}
$$

$V_{f}$ : Volume of the glass fiber

$W_{f}$ : Weight of glass fiber

$\rho_{m}:$ Specific gravity of resin

$\rho_{f}$ : Specific gravity of glass fiber

\section{A.2: Elastic constants of the unidirectional reinforcement}

$$
\begin{aligned}
& E_{L}=E_{f} \nu_{f}+E_{m}\left(\mathrm{I}-V_{f}\right) \\
& \frac{1}{E_{T}}=\frac{1.36\left(K_{f}-K_{m}\right)}{\left(K_{f}-K_{m}\right)^{2}-\left(v_{f} K_{f}-v_{m} K_{m}\right)^{2}}+\frac{1-1.05 \sqrt{v_{f}}}{E_{m}} \\
& v_{L}=\frac{1.05 \sqrt{v_{f}}\left(v_{f}-v_{m}\right) K_{f}}{K_{f}-K_{m}}+v_{m} \\
& v_{T}=\frac{v_{L} E_{T}}{E_{L}} \\
& \frac{1}{G_{L T}}=\frac{1.36}{G_{f}-G_{m}}+\frac{1-1.05 \sqrt{V_{f}}}{G_{m}} \\
& K_{f}=\frac{E_{f}}{1-v_{f}^{2}} \quad K_{m}=\frac{E_{m}}{1-v_{m}^{2}} \\
& G_{f}=\frac{E_{f}}{2\left(1+v_{f}\right)} \quad G_{m}=\frac{E_{m}}{2\left(1+v_{m}\right)}
\end{aligned}
$$

\section{A.3: Modulus of elasticity of the mat (chopped strand mat)}




$$
\begin{gathered}
E=\frac{\left[E_{L}+E_{T}-2 E_{L} v_{T}+4 G_{L T}\left(1-v_{L} v_{T}\right)\right]\left(E_{L}+E_{T}+2 E_{L} v_{T}\right)}{3\left(E_{L}+E_{T}\right)+2 E_{L} v_{T}+4 G_{L T}\left(1-v_{L} v_{T}\right)} \\
G=\frac{E_{L}+E_{T}-2 E_{L} v_{T}+4 G_{L T}\left(1-v_{L} v_{T}\right)}{8\left(1-v_{L} \nu_{T}\right)} \\
v=\frac{E_{L}+E_{T}+6 E_{L} \nu_{T}-4 G_{L T}\left(1-v_{L} v_{T}\right)}{3\left(E_{L}+E_{T}\right)+2 E_{L} v_{T}+4 G_{L T}\left(1-v_{L} v_{T}\right)}
\end{gathered}
$$

\section{A.4: Modulus of elasticity of the helical winding FW} material

$$
\begin{aligned}
& 1 / E_{x}=\left(1 / E_{x o}\right)-x^{2} G_{x y o} \\
& 1 / E_{y}=\left(1 / E_{y o}\right)-\varphi^{2} G_{x y o} \\
& v_{x} / E_{x}=v_{y} / E_{y}=\left(v_{x o} / E_{x o}\right)+x \varphi G_{x y o} \\
& \frac{1}{G_{x y}}=\frac{1}{G_{x y o}}-\frac{\chi\left(\chi+\varphi v_{y o}\right)}{1-v_{x o} v_{y o}} E_{x o}-\frac{\varphi\left(\varphi+\chi v_{x o}\right)}{1-v_{x o} v_{y o}} E_{y o} \\
& \frac{1}{E_{x o}}=\frac{\cos ^{4} \alpha}{G_{x y o}}-\frac{\chi\left(\chi+\varphi v_{y o}\right)}{1-v_{x o} v_{y o}} E_{x o}-\frac{\varphi\left(\varphi+\chi v_{x o}\right)}{1-v_{x o} v_{y o}} E_{y o} \\
& \frac{1}{E_{y o}}=\frac{\sin ^{4} \alpha}{E_{L}}+\frac{\cos ^{4} \alpha}{E_{T}}+\left(\frac{1}{G_{L T}}-\frac{2 v_{L}}{E_{L}}\right) \sin ^{2} \alpha \cdot \cos ^{2} \alpha \\
& \frac{1}{G_{x y o}}=\left(\frac{1+v_{L}}{E_{L}}+\frac{1+v_{T}}{E_{T}}\right) \sin ^{2} 2 \alpha+\frac{1}{G_{L T}} \cos ^{2} 2 \alpha \\
& \frac{v_{x o}}{E_{x o}}=\frac{v_{y o}}{E_{y o}}=\frac{v_{L}}{E_{L}}\left(\cos ^{4} \alpha+\sin ^{4} \alpha\right)+\left(\frac{1}{G_{L T}}-\frac{1}{E_{L}}-\frac{1}{E_{T}}\right) \frac{\sin ^{2} 2 \alpha}{4} \\
& \chi=\left[\frac{\sin ^{2} \alpha}{E_{T}}-\frac{\cos ^{2} \alpha}{E_{L}}+\frac{1}{2}\left(\frac{1}{G_{L T}}-2 \frac{v_{L}}{E_{L}}\right) \cos 2 \alpha\right] \sin 2 \alpha \\
& \varphi=\left[\frac{\cos ^{2} \alpha}{E_{T}}-\frac{\sin ^{2} \alpha}{E_{L}}-\frac{1}{2}\left(\frac{1}{G_{L T}}-2 \frac{v_{L}}{E_{L}}\right) \cos 2 \alpha\right] \sin 2 \alpha
\end{aligned}
$$

\section{References}

[1] Takashi Shimosakon, Shinichi Tamura, Yoshinori Nishino, "GPI standard Corrosion FRP High Pressure Pipes for Oil \& Gas Well (Design standard of GPI standard Piping Joint) 'Commentary', The Piping Engineering,vol.56, no.9,pp.17-25, 2014.

[2] Yoshinori Nishino, About the long distance FRP pipe, The Piping Engineering (Requested paper HA05-20, 1985) Japan Industrial Publishing Co., Ltd.

[3] Nishino,Yamamoto,Uda,Kanazawa, Studies on the secondary adhesive strength of FRP pipe [double wraped] joint factor, Reinforced Plastics, 28-10 (1984), 424-429.
[4] Y. Nishino, M. Yamamoto, T. Uda: FRP pipe joint design method, Reinforced Plastics,30-2(1984), 52-58

[5] Nishino, Yamamoto, Uda, Kanazawa, Nonlinear analysis of macroscopic finite element method of FRP pipe joint, Reinforced Plastics,28-3(1982),390-402

[6] Nishino,Yamamoto, Uda, Kanazawa, Studies on secondary adhesive strength of FRP pipe joint, Reinforced Plastics28-2(1982),390-402

[7] Y. Nishino, M. Yamamoto, T. Uda: Experiments on Peeling Off of Reinforcement Layers from Inner Surface of FRP Pipe Due to water Flow Part 1: Peel off characteristics neglecting aging deterioration. The journal of the Textile Machinery society of Japan, Transactions, 33-3(1987)

[8] T. Shimosakon, T. Iwatani, R. Takeda, S. Tamura, and Y. Nishino, "Toward the GPI standard: Evaluation method of FRP high pressure pipes for oil and gas well use, Global Business Society,pp.65-74, vol.2, no.1, 2014.

[9] Toshiharu Iwatani, Masaki Nishino, Yoshinori Nishino, Yasuhiro Iguchi, Takio Shimosakon, Shinichi Tamura: Design Method of API High Pressure Pipe, Proc. of The Sixth Korea-Japan Joint Symposium on Composite Materials, pp.22-23, Pohang, Korea (Oct.31-Nov.2,2007)

[10] Takashi Shimosakon, Toshiharu Iwatani, Pushpendra Kumar, Yutaka Oku, Shinichi Tamura, Yoshinori Nishino, "Technology development for revival of the corroded oil well casing: Development of dual casing pipe," International Conference on Composites for 21th Century: Current and Future Trends (ICC-CFT2011), Bangalore, India

[11] Takashi Shimosakon, Toshiharu Iwatani, Pushpendra Kumar, Shinichi Tamura, Yoshinori Nishino, "Screw joint parts for high pressure and low cost FRP pipes," Proceedings of International Conference and Exhibition on Reinforced Plastics (ICERP 2011), March 2-4, 2011, Mumbai, India.

[12] Shinichi Tamura, Yoshinori Nishino, "Towards the GPI Standard," 1st International Symposium on GPI Standard (GPI 2013), Osaka, pp.87-92, March 2, 2013.

[13] T. Iwatani, T. Shimosakon, R. Takeda, S. Tamura, and Y. Nishino, "Toward the GPI standard: Evaluation method for oil and gas well FRP high pressure pipes,"1st International Symposium on GPI Standard (GPI 2013), Osaka, pp.93-106, March 2, 2013.

[14] Takashi Shimosakon, Toshiharu Iwatani, Ryo Takeda, Shinichi Tamura, and Yoshinori Nishino, "Basic joint design of anti-corroding high pressure pipes for oil well: Tolerance of GPI pipes," 2nd International Symposium on GPI Standard (GPI-2 2013), pp.35-40, 2013.

[15] Hiroyuki Sugiyama, Toshiharu Iwatani, Takashi Shimosakon, Shinichi Tamura, and Yoshinori Nishino, "Bonding strength of FRP pipe joint," 2nd International Symposium on GPI Standard (GPI-2 2013), pp.41-44, 2013.

[16] Takashi Shimosakon, Taiga Tatsumi, Rui Nishino, Shinichi Tamura, Yoshinori Nishino, Study on oil well pipe traceability system by IC chip label (first report), 5th Symposium of Global Business Society, pp. 106-171. 